\title{
From less invasive to minimal invasive extracorporeal circulation
}

\author{
Kyriakos Anastasiadis^, Polychronis Antonitsis^, Apostolos Deliopoulos, Helena Argiriadou \\ Cardiothoracic Department, AHEPA University Hospital, Thessaloniki, Greece \\ Contributions: (I) Conception and design: K Anastasiadis; (II) Administrative support: P Antonitsis, H Argiriadou; (III) Provision of study materials \\ or patients: H Argiriadou, A Deliopoulos; (IV) Collection and assembly of data: K Anastasiadis, P Antonitsis; (V) Data analysis and interpretation: \\ KAnastasiadis, H Argiriadou, P Antonitsis; (VI) Manuscript writing: All authors; (VII) Final approval of manuscript: All authors. \\ Correspondence to: Polychronis Antonitsis. Cardiothoracic Department, AHEPA University Hospital, S. Kyriakidi 1, 54636 Thessaloniki, Greece. \\ Email: antonits@auth.gr.
}

\begin{abstract}
Development of minimally invasive cardiac surgery (MICS) served the purpose of performing surgery while avoiding the surgical stress triggered by a full median sternotomy. Minimizing surgical trauma is associated with improved cosmesis and enhanced recovery leading to reduced morbidity. However, it has to be primarily appreciated that the extracorporeal circulation (ECC) stands for the basis of nearly all MICS procedures. With some fundamental modification and advancement in perfusion techniques, the use of ECC has become the enabling technology for the development of MICS. Less invasive cardiopulmonary bypass (CPB) techniques are based on remote cannulation and optimization of perfusion techniques with assisted venous drainage and use of centrifugal pump, so as to facilitate the demanding surgical maneuvers, rather than minimizing the invasiveness of the CPB. This is reflected in the increased duration of CPB required for MICS procedures. Minimal invasive Extracorporeal Circulation (MiECC) represents a major breakthrough in perfusion. It integrates all contemporary technological advancements that facilitate best applying cardiovascular physiology to intraoperative perfusion. Consequently, MiECC use translates to improved end-organ protection and clinical outcome, as evidenced in multiple clinical trials and meta-analyses. MICS performed with MiECC provides the basis for developing a multidisciplinary intraoperative strategy towards a "more physiologic" cardiac surgery by combining small surgical trauma with minimum body's physiology derangement. Integration of MiECC can advance MICS from non-full sternotomy for selected patients to a "more physiologic" surgery, which represents the real face of modern cardiac surgery in the transcatheter era.
\end{abstract}

Keywords: Minimal invasive; cardiac surgery; extracorporeal circulation (ECC); cardiopulmonary bypass (CPB); minimal invasive Extracorporeal Circulation (MiECC)

Submitted May 02, 2020. Accepted for publication Aug 06, 2020.

doi: $10.21037 /$ jtd-20-1830

View this article at: http://dx.doi.org/10.21037/jtd-20-1830

\section{Introduction}

The development of extracorporeal circulation (ECC) in 1953 by John Gibbon heralded the era of modern cardiac surgery, that is the open-heart surgery. The strengths of traditional cardiopulmonary bypass (CPB) require little explanation. Nearly 70 years of continuous use has demonstrated the ability of CPB to enable the practice of cardiac surgery. Since then, advances in surgical technique, anesthesia and intensive care management markedly improved clinical outcomes. Obviously, from the birth of open-heart surgery, the cardiac surgeon dominated as the major stakeholder the cardiac operating room (OR). Thus, the quest for reducing morbidity and mortality related to cardiac surgery focused primarily on further advancing

\footnotetext{
^ ORCID: Kyriakos Anastasiadis, 0000-0001-7837-3446; Polychronis Antonitsis, 0000-0002-5451-4651.
} 
surgical technique, rather than the other related specialties involved, that is anesthesia and perfusion. The advancement in ECC that should be involved in this pursuit was systematically ignored.

\section{Evolution of MICS}

Minimally invasive cardiac surgery (MICS) emerged as an innovative technique for performing cardiac surgery obviating the surgical stress induced by a full sternotomy and hence reducing morbidity and mortality. Main benefits were reduced surgical trauma with a more satisfactory cosmetic result as well as enhanced recovery. The America Heart Association defined "minimal invasiveness" as smaller sternotomy and non-sternotomy strategies aided by robotic or video-assisted technologies (1). This concept implies that reduction of the "invasiveness" of a cardiac surgical procedure lies predominantly in the selection of an alternative approach securing optimal operative outcome.

Moreover, it has to be mostly appreciated that ECC stands for the basis of nearly all standard or minimally invasive cardiac procedures. With some fundamental modification and advancement in perfusion techniques, the use of CPB has become the enabling technology for the development of MICS. This component of MICS though is usually underestimated or even deliberately neglected as pointed out. It has to be acknowledged that the two of the three major disciplines in cardiac OR (surgery and anesthesiology) have significantly improved their performance and clinical results while they underestimate the crucial role of perfusion, considering perfusionists as technicians. However, perfusion has also significantly developed throughout years and hence the immense need for improving results in cardiac surgery; this best applies cardiovascular physiology in clinical practice, and it is proved to enhance outcome.

\section{Rationale for MICS}

Cardiac surgery is considered, by definition, "nonphysiologic". This explains, at large, the significant morbidity and subsequent mortality observed, especially in complex, high-risk and emergency procedures. According to the latest report of the largest cardiac surgical registry, the STS database, a complications rate of $30 \%$ is still anticipated even in elective isolated mitral valve procedures or combined valvular and coronary surgery (2).
In the same breath speaking of respect for perfusion capability, there are often cries for its elimination, mainly due to the systemic inflammatory response triggered and end-organ damage (3). During the past two decades the conduct of $\mathrm{CPB}$, at least for coronary artery bypass graft (CABG) surgery, has been under a marketing attack with the development of "off-pump" revascularization surgery (OPCAB). Despite the early encouraging results, emerging mainly from large cohort studies, favoring OPCAB in terms of reducing postoperative morbidity, long-term data from multicenter randomized studies brought the on-pump again in the forefront of coronary revascularization surgery (4). Recently published results from large-scale meta-analyses proved that OPCAB was related to increased rate of incomplete revascularization; this led to increased 3-year all-cause mortality in patients with left main stem disease (EXCEL trial) as well as higher risk of cardiovascular death in patients with multiple arterial grafts (ART trial) $(5,6)$. These findings further enhanced the fundamental role of ECC in open-heart surgery.

\section{Less invasive ECC techniques for MICS}

From the early years of MICS it was recognized that advancement of CPB circuitry, cannulas, and techniques was imperative in order to facilitate the unique demands of minimally invasive procedures (7). Thus, MICS opted for less invasive ECC techniques on the grounds of connecting peripherally the $\mathrm{CPB}$ and modifying perfusion techniques so as facilitating the demanding and delicate surgical maneuvers; remote access perfusion was, thus, implemented.

\section{Cannulation strategies}

Optimal cannulation strategy, which is crucial in such circumstances, is dictated by the surgical procedure and the preferred approach. The femoral artery is the most common cannulation site. Alternatively, the right axillary artery can be cannulated, utilizing a graft interposition, in situations where the femoral approach is prohibitive because of atherosclerosis or tortuosity (8). Industry greatly facilitated uncomplicated arterial cannulation by designing special arterial cannulas for MICS that can be inserted either percutaneously or through direct vision using the Seldinger technique. Furthermore, remote access venous cannulation is usually performed percutaneously with a long femoral venous cannula Proper placement is guided by 
transesophageal echocardiography. In certain conditions, like patients undergoing right-sided heart procedures or in large patients undergoing mitral valve surgery, a second internal jugular venous cannula may be placed percutaneously to facilitate venous drainage (7).

The smaller-caliber venous cannulas used for MICS have a higher resistance to flow and, hence, gravity venous drainage on CPB is insufficient for achieving optimal flow. Thus, augmented venous drainage is preferred by utilizing either vacuum assisted-venous drainage (VAVD) or kineticassisted venous drainage (KAVD) when using a centrifugal pump $(9,10)$. The VAVD comprises application of negative pressure with a vacuum regulator to a non-vented hard-shell venous reservoir; the net negative pressure is continuously monitored to avoid hemolysis (7).

\section{Aortic cross-clamping}

Aortic cross-clamping is most commonly performed with specially designed Chitwood telescopic clamps placed either directly through the operative field, or through a separate chest incision. Transthoracic aortic crossclamping is inexpensive and used by most surgeons; apparently, it requires an additional aortic cannulation site for antegrade cardioplegia delivery and root venting. Alternatively, endovascular aortic cross-clamping can be utilized with delivery of an endoaortic balloon placed under transesophageal guidance, which also enables antegrade cardioplegia delivery, aortic root venting, and aortic root pressure monitoring (11). Endovascular pulmonary artery venting is also feasible.

\section{Myocardial protection}

In general, MICS opted for antegrade delivery of Bretschneider (Custodiol) or Del Nido cardioplegia solutions, while retrograde delivery through the coronary sinus with the use of special catheters or intermittent antegrade delivery is considered more challenging (12).

It is obvious that optimal perfusion is not an accessory, but a core component of MICS strategy. The advancement from conventional CBP (cCPB) towards an improved perfusion circuit is described, by some groups, as "optimized ECC" (opECC) (13). This represents an upgraded and more versatile perfusion circuit that integrates selected $\mathrm{CPB}$ technological advancements to the standard perfusion circuit (Figure 1) (14).

\section{The minimal invasive Extracorporeal Circulation (MiECC)}

\section{Rationale}

Considering all technical modifications presented above, it is obvious that "less invasive" ECC employs techniques for facilitating MICS rather than minimizing the invasiveness of the CPB itself (15). Thus, there is a misleading concept about "minimizing the pump" in MICS; "less invasive" ECC strategies apply to the optimization of the surgical setting (surgeon perspective) rather than to the pursuit of a truly minimally invasive, that is a "more physiologic" cardiac surgery (physiology perspective) (16). Hence, remote access $\mathrm{CPB}$, utilization of transcatheter techniques, application of assisted venous drainage, etc. stand for facilitating primarily the surgeon so as to be comfortable while employing his technique, rather than ameliorating the patient's physiology derangement from the application of ECC.

On the contrary, it is possible that MICS procedures may scale up the side effects of ECC to the patient, which may be assumed when considering data derived from available large-scale studies and meta-analyses. According to the Phan et al. Bayesian network meta-analysis, the right mini-thoracotomy approach for aortic valve replacement (AVR) was associated to a significantly increased CPB and cross-clamp time compared to sternotomy approach $(\mathrm{P}=0.001)$ (17). The same applies to minimally invasive mitral procedures; in a recently published meta-analysis by Moscarelli et al. including 1,905 patients, minimally invasive mitral valve surgery was associated with a mean 32 mins of additional $\mathrm{CPB}$ duration $(\mathrm{P}<0.01)$ compared to sternotomy approach (18). Even in totally endoscopic CABG (TECAB) the current trend favors implementation of CPB $(19,20)$ rather than operating off-pump. Thus, an oxymoron comes up: how could MICS perspective minimize the operative burden through minimizing surgical trauma, while at the same time adds to body's physiology derangement by increasing duration of cCPB? (Figure 2).

It becomes evident that MICS, on the grounds of minimizing patient's surgical trauma, cannot be accomplished without implementing an optimal CPB strategy which truly minimizes CPB side-effects that currently stands for MiECC. The Minimal Invasive Extracorporeal Technologies International Society (MiECTiS) considers MiECC as a strategy which refers mainly to invasiveness of the system and not 


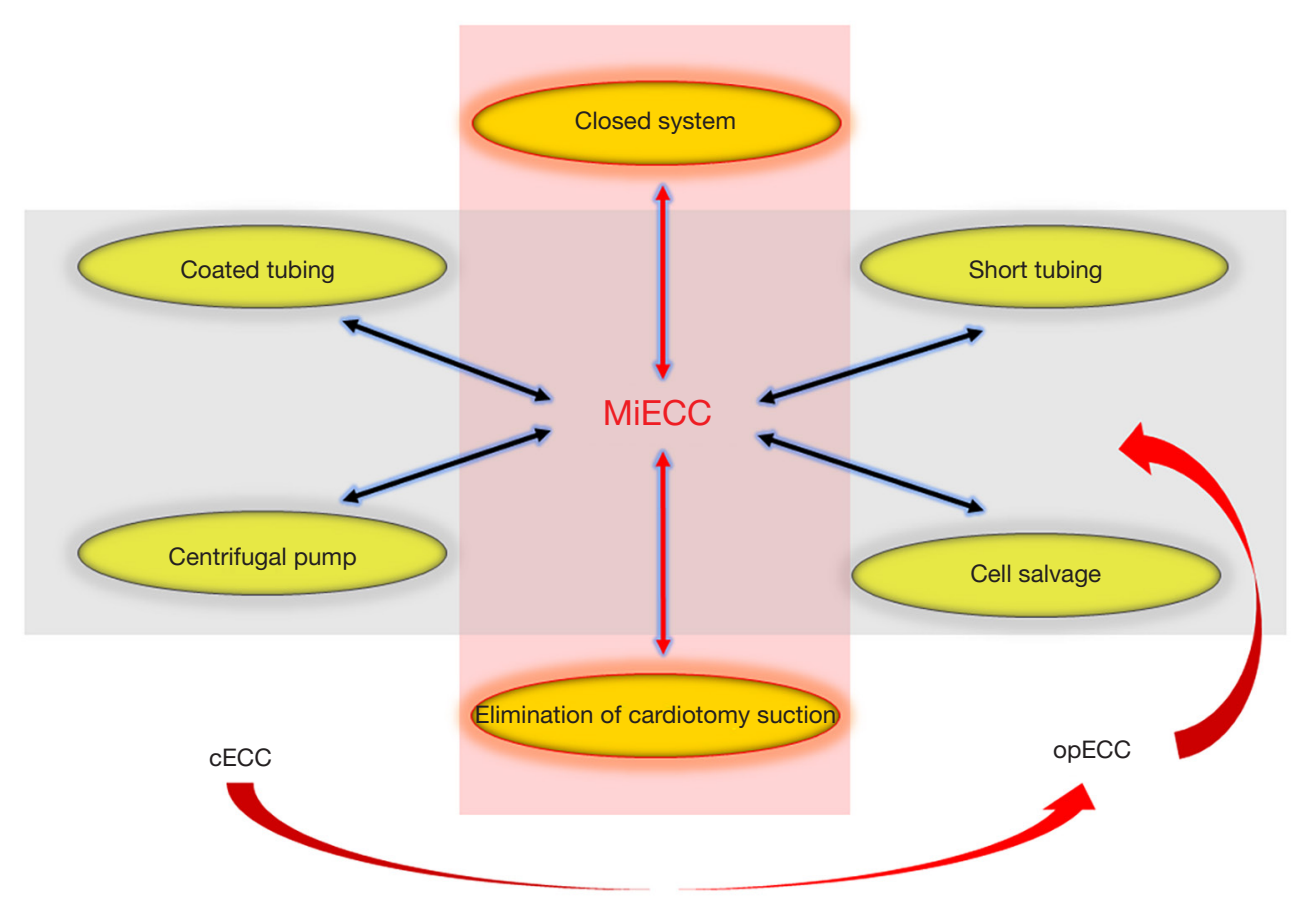

Figure 1 Minimal invasive extracorporeal circulation (MiECC) integrates the major advancements in CPB technology in one circuit, while "optimized" extracorporeal circulation circuits (opECC) use some of the illustrated components so as to upgrade conventional extracorporeal circulation (cECC). Less invasive extracorporeal circulation for performing MICS utilizes the horizontal technological advancements (grey zone) and can be considered as opECC. On the other hand, MiECC comprises full-spectrum of advancements and it is based mainly on the vertical components of CPB technology (red zone). Thus, when MICS encompasses MiECC, it utilizes the best available perfusion strategy; MICS, minimal invasive cardiac surgery.

only to the size of the ECC circuit. MiECC integrates all advancements in perfusion technology that have shown positive clinical or subclinical results. This is associated with low systemic inflammation, improved blood product management based on low hemodilution as well as preserved anticoagulation based on enhanced biocompatibility (21). Moreover, MiECTiS advocates that MiECC strategy is multidisciplinary, involving all stakeholders of the surgical OR (surgery, anesthesiology and perfusion) and it is mandatory so as to get the maximum benefit from this technology. Thus, obviously in the era of MiECC, MICS should complement its techniques with MiECC strategy.

\section{Components}

Regarding its components, MiECC encompasses: closed totally biocompatible circuit with short tubing length and minimum priming volume; centrifugal pump; membrane oxygenator; venous bubble trap or venous air removing device; heat exchanger; cardioplegia system and a shed blood management device. Additional components that could be integrated into a MiECC system include: vents (pulmonary artery, aortic root or pulmonary vein), soft bag (shell) reservoir, hard shell reservoir (in modular systems) as well as an arterial filter (21). Thus, the key features of this system are the closed, autoregulated circuit (when the patient's venous compartment acts as the reservoir), the low prime volume producing minimal hemodilution, the avoidance of blood-air interaction as well as shed blood recirculation.

\section{Classification}

Classification of MiECC systems (Figure 3) was proposed by Anastasiadis et al. and was subsequently universally adopted by MiECTiS, consolidates the evolution of MiECC systems over the past two decades (22). Original MiECC systems (classified as type I) are literally Extracorporeal Life Support 


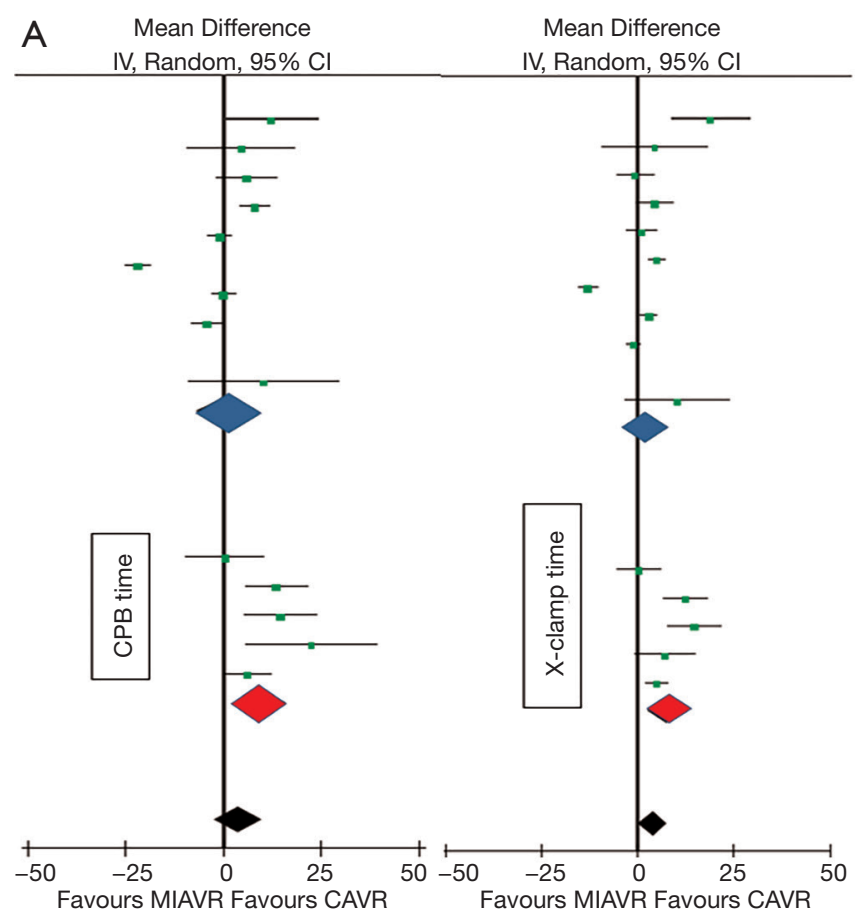

B

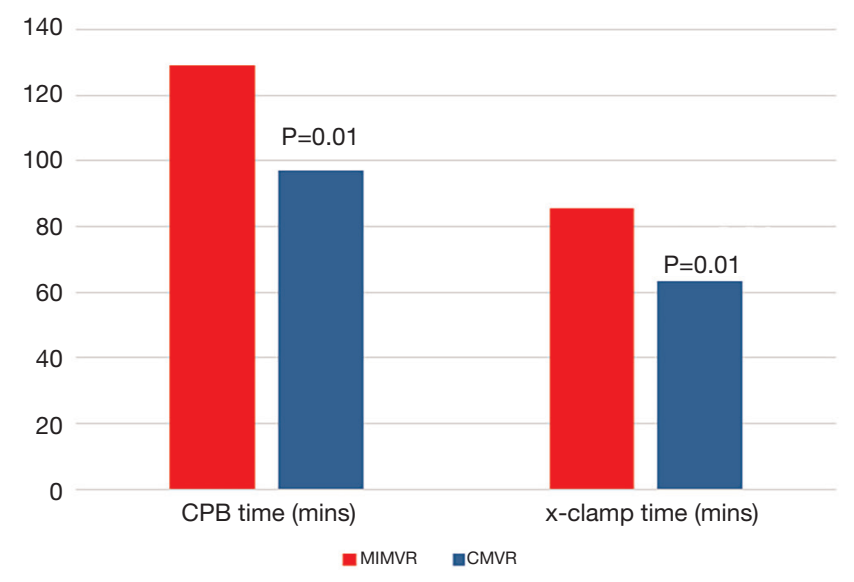

Figure 2 Duration of CPB and x-clamp time in major MICS procedures. (A) Forest plot of the mean difference in CPB and $\mathrm{x}$-clamp duration between minimally invasive aortic valve replacement (MIAVR) and conventional one - sternotomy (CAVR) [modified from (17)]. The blue diamond indicates sternotomy approach, while the red diamond indicates mini-thoracotomy. The latter is associated with significantly increased duration of CPB and x-clamp time. (B) The same trend applies to minimally invasive mitral valve procedures (MIMVR) (red bars) compared to conventional ones - sternotomy (CMVR) (blue bars) [data extracted from (18)]. CPB, cardiopulmonary bypass; MICS, minimal invasive cardiac surgery.

(ECLS) circuits with an additional line to administer cardioplegia. Concerns emerged regarding air entrainment into the venous line that could cause the centrifugal pump to stop prompted the integration of venous bubble trap or venous air removing devices into the system (type II design), which enhanced safety of the procedure. The need for controlling blood volume (mainly in intracardiac procedures) mandated integration of a soft bag (soft shell) reservoir into the system (type III). Expansion of utilizing MiECC systems for performing complex procedures opted for the development of modular (hybrid) systems, which integrate an open hard shell reservoir as an accessory (standing-by) component readily available for conversion to an open system in case of any unexpected perfusion scenario: massive air entry or excessive shed blood loss (type IV). Contemporarily, modular systems overcome any safety concern or technical difficulty enabling performance of fullspectrum cardiac surgery.

\section{Special considerations during MICS on MiECC}

\section{Role of surgeon}

The surgeon, as previously described, represents the major stakeholder of the surgical team in cardiac OR. When it comes to MICS on MiECC both techniques demand delicate surgical maneuvers. In this setting, it is of utmost importance for the surgeon not only to comprehend perfusion technology, but to deeply understand MiECC unique characteristics and its differences from cCPB, in order to adapt surgical technique to the special requirements of MiECC perfusion (23). Special care must be taken to secure "air tightness" during cannulation at all sites. The surgeon should primarily appreciate that when operating on MiECC shed blood does not recirculate into the closed system and it is literally "wasted" from patient's intravascular compartment. Continuous communication with the perfusionist and the anesthesiologist is critical for 


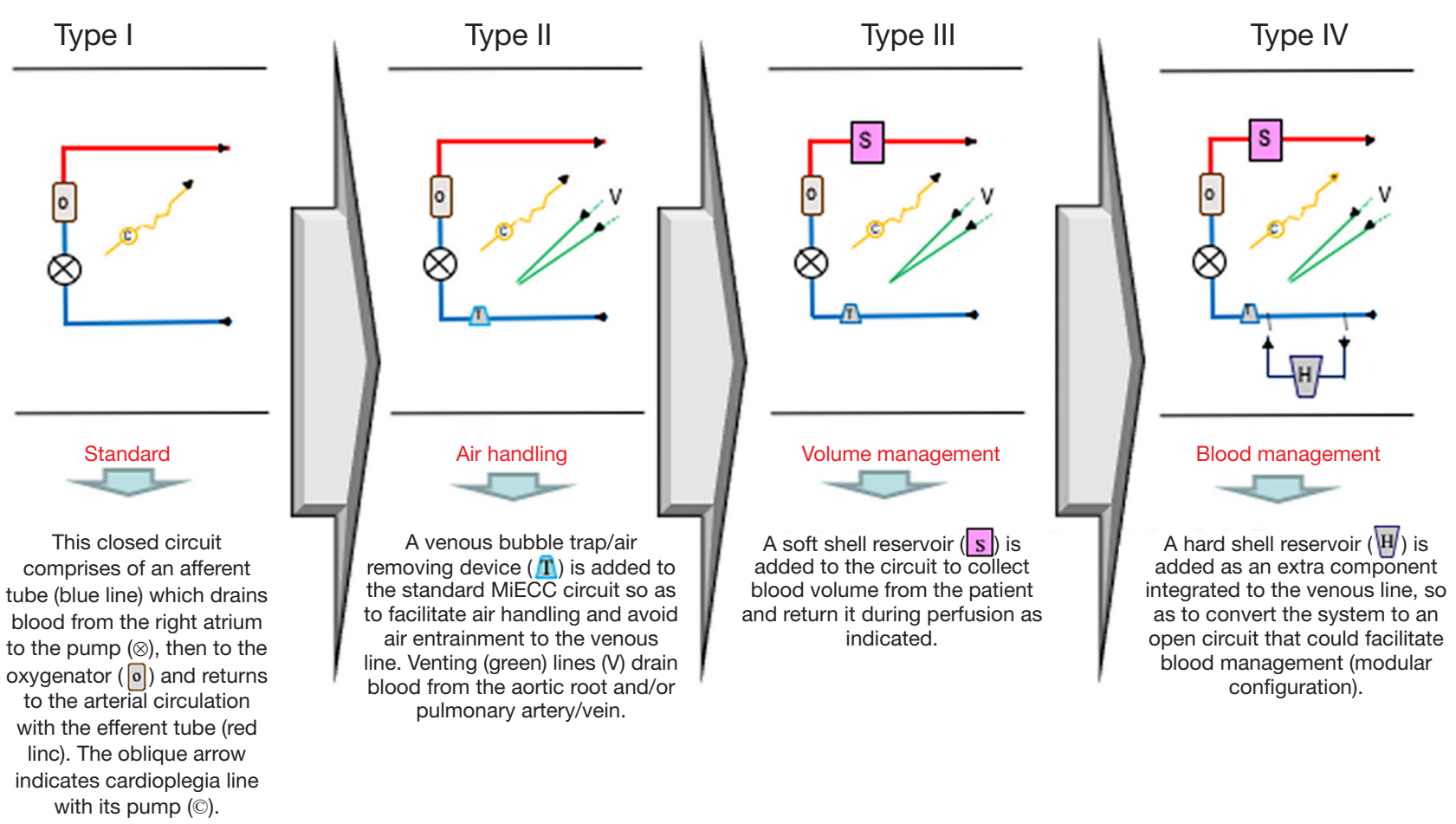

Figure 3 Schematic classes of MiECC circuits. X, pump; O, oxygenator; C, cardioplegia; T, bubble trap/air removing device; V, vent (aortic/ pulmonary); $\mathrm{S}$, soft shell reservoir; $\mathrm{H}$, hard shell reservoir.

establishing optimal conditions during surgery, i.e., when removing a vent in order to avoid accidental air entrainment into the system.

\section{Role of anesthesiologist}

The anesthesiologist plays a significant role, as integration of the anesthetic strategy into a multidisciplinary perioperative MICS on MiECC strategy secures a unanimous and discrete plan for managing the patient. For this reason, it is considered mandatory to acquire advanced knowledge on MiECC perfusion technology (24). The closed MiECC circuit mandates judicious use of fluids, so as to eliminate hemodilution. A thorough monitoring strategy for securing body's homeostasis and preventing derangements is important for a smooth perioperative course. MICS on MiECC creates conditions for fast-track (25) or ultra-fasttrack extubation management due to minimal perioperative surgical trauma $(26,27)$. Thus, an anesthetic strategy based on short-acting intravenous drugs, like propofol and remifentanil is recommended. A contemporary Point-ofCare (POC) heparin/protamine coagulation management in the OR includes thromboelastometry, platelets function tests and heparin-protamine individualized titration. The unique characteristics of MiECC circuit allow for the application of a low anticoagulation protocols. An ACT value of $300 \mathrm{sec}$ for CABG and of $400 \mathrm{sec}$ for valve and complex procedures is safe and it is recommended $(28,29)$. Moreover, individualized heparin and protamine titration is recommended according to the joined EACTS/EACTA guidelines (30).

\section{Role of perfusionist}

The perfusionist when operating on MiECC, should act not just like a technician but as a clinical scientist securing endorgan protection; this especially applies in the demanding procedures of MICS. Principles of closed-circuit hemodynamics/physiology should be primarily appreciated. Volume management is crucial; by utilizing a centrifugal pump, flow is largely dependent on a balance between the filling status of the patient and systemic vascular resistance (preload - afterload dependency). Special attention should be given in cases when KAVD create excessive negative pressure in the venous line; this increases shear stress and leads to increased hemolysis. Careful venous cannula size 


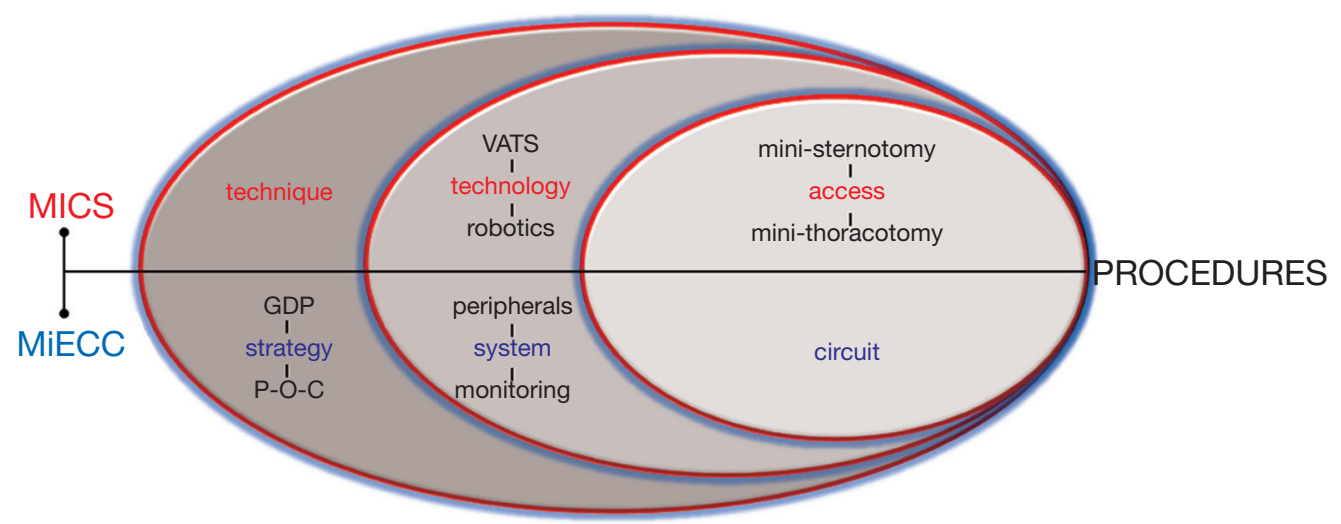

Figure 4 Schematic representation of the proposed MICS - MiECC approach towards "more physiologic" cardiac surgery: MICS and MiECC comprise procedures which incorporate respectively: (I) the core which is the access (mini-sternotomy or mini-thoracotomy) and the circuit, (II) the technology (VATS or robotics) and the system (peripherals and monitoring), and (III) the technique and the strategy (GDP and POC). GDP, goal-directed perfusion; MICS, minimal invasive cardiac surgery; MiECC, minimal invasive extracorporeal circulation., POC, Point-of-Care heparin/protamine and coagulation management.

selection is important to avoid venous collapse around the cannula (9). Cardioplegia strategy during surgery on MiECC is based mainly on blood miniplegia (i.e., Calafiore regime) in order to avoid excessive volume administration. As previously described, most centers using MICS prefer single-dose cardioplegia regimes, though they add significant volume to the circuit. In such scenario when using a MiECC system the extra volume could either be collected by extracting it from the right atrium or eliminated by ultrafiltration.

In order to obtain optimal results operating on MiECC, the operational learning curve has been evaluated and is significantly less steep compared to MICS training (31).

\section{A MICS-MiECC strategy towards a "more physiologic" cardiac surgery}

\section{Goal-directed perfusion (GDP)}

The concept of "more physiologic" perfusion has already been established in the literature (32). Allied to this, MICS represents a strong pillar of the multidisciplinary strategy towards "more physiologic" cardiac surgery when combined with MiECC (16) (Figure 4). Advancement in surgical techniques, as promoted with MICS, is considered inadequate for accomplishing such a goal without incorporating optimal perfusion that MiECC offers. Our proposed perioperative MiECC multidisciplinary strategy is based on GDP with detailed in-line monitoring and real- time adjustment rather than incremental correction of any derangement (16). This translates to a "prevent rather than correct" policy. The ultimate target when combining MICS with MiECC is to operate all case-mix (low- and high-risk patients and complex procedures) as comfortably and effectively, in terms of hemodynamic and metabolic integrity, as operating a low-risk case (13).

The principles for a "more physiologic" cardiac surgery is: the small surgical trauma from MICS (17) and the minimum body's physiology derangement from MiECC use. Regarding the latter, it is well established nowadays that MiECC best applies physiology during intraoperative perfusion by attaining elevated mean arterial pressure and preserved systemic vascular resistance for any given flow (33); thereby significantly reducing need for vasoactive medication (34). In cellular level, its clinical superiority lies in the integrity of microcirculation when compared to cCPB. As stated, cardiac surgery is a 'nonphysiologic' intervention that is inevitably associated with microcirculatory alterations (35); thus, it has been proven that CPB reduces perfused microvessels to $50 \%$ of baseline (36). On the contrary, it has been proved that MiECC optimizes perfusion by preserving and enhancing recovery of microcirculatory blood; this effect is primarily attributed to significantly reduced hemodilution and microcirculatory hypoperfusion (37), which promotes recovery of microvascular flow (38). Preservation of microcirculatory integrity ameliorates end-organ damage 
Table 1 Summary of evidence-based practice guidelines (21)

\begin{tabular}{|c|c|}
\hline Recommendation & Level of evidence \\
\hline $\begin{array}{l}\text { MiECC systems reduce hemodilution and better preserve hematocrit as well as reduce postoperative bleeding } \\
\text { and the need for RBC transfusion }\end{array}$ & A \\
\hline MiECC systems reduce the incidence of postoperative atrial fibrillation & A \\
\hline MiECC systems preserve renal function & A \\
\hline \multicolumn{2}{|l|}{ Class IIA } \\
\hline Inflammatory response assessed by specific inflammatory markers is attenuated with use of MiECC & $\mathrm{B}$ \\
\hline MiECC systems can reduce cerebral gaseous microembolism and preserve neurocognitive function & $\mathrm{B}$ \\
\hline \multicolumn{2}{|l|}{ Class IIB } \\
\hline $\begin{array}{l}\text { Within a MiECC strategy, less thrombin generation may permit reduced heparin dose targeted to shorter ACT } \\
\text { times. When such a strategy is followed, individual heparin dose should be determined using heparin dose- } \\
\text { response monitoring systems }\end{array}$ & $\mathrm{B}$ \\
\hline MiECC appears to offer survival benefit in terms of lower 30-day mortality after CABG procedures & $\mathrm{B}$ \\
\hline $\begin{array}{l}\text { Use of short-acting opioids in combination with propofol or volatile anesthetics, and hypnotic effect monitoring } \\
\text { by processed EEG, is recommended for induction and maintenance of anesthesia for MiECC-based surgery. } \\
\text { TEE findings pertinent to institutional management of MiECC should be communicated during the preoperative } \\
\text { surgical safety time out }\end{array}$ & $\mathrm{C}$ \\
\hline
\end{tabular}

ACT, activated clotting time; CABG, coronary artery bypass grafting; EEG, electroencephalogram; MiECC, minimal invasive extracorporeal circulation; RBC, red blood cells.

and explains most of MiECC clinical benefits.

\section{Comparison of MiECC and $c C P B$}

The superiority of MiECC over CCPB in clinical practice has been well-established throughout the last decade with large-scale randomized studies and meta-analyses (13). The position paper produced by MiECTiS provides a detailed overview of evidence-based recommendations for clinical practice, summarized in Table 1 (21). According to this consensus, MiECC clinical benefits stem from the attenuation of systemic inflammatory response and the reduction in gaseous microembolic load to the brain, which ultimately lead to improved end-organ protection; this is evidenced by the reduction in the incidence of postoperative atrial fibrillation and preservation of renal and myocardial function (21). Moreover, a survival benefit in CABG on MiECC as compared to cCPB $(0.5 \%$ vs. $1.7 \% ; \mathrm{P}=0.02)$ was evidenced in a large meta-analysis including 2,700 patients from 24 randomized controlled trials (39). This finding was verified in subsequent large-scale studies. Ried et al. in a propensity score analysis reported reduced 30-day mortality in 3,139 patients undergoing elective CABG $(0.8 \%$ for MiECC vs. $2.7 \%$ for $\mathrm{cCPB}$; $\mathrm{P}<0.001)(40)$. Moreover, in a large network meta-analysis including 22,778 patients undergoing CABG, Kowalewski et al. proved that MiECC significantly reduced 30-day all-cause mortality compared to $\mathrm{CCPB}$ and OPCAB (1.20\% for MiECC vs. $1.94 \%$ for OPCAB vs. $2.59 \%$ for $\mathrm{CCPB}$ ) (41). The hierarchy of treatments after probability analysis established the superiority of MiECC; thus, it is obvious that MiECC should not represent just a compromise but the dominant technique for performing CABG (42). Results of the main meta-analyses and randomized studies comparing MiECC with $\mathrm{cCPB}$ and $\mathrm{OPCAB}$ are summarized in Table 2. In terms of cost-effectiveness, a well-designed economic analysis leveraging data from four different countries, showed that MiECC is considered dominant technique (associated with 
Table 2 Summary of major meta-analyses and randomized studies comparing MiECC to cCPB and OPCAB

\begin{tabular}{|c|c|c|c|c|c|c|c|c|c|}
\hline Publication & $\begin{array}{l}\text { Patients } \\
\text { number }\end{array}$ & Transfusion & $\begin{array}{l}\text { Blood } \\
\text { loss }\end{array}$ & Stroke & $\begin{array}{l}\text { Myocardial } \\
\text { protection }\end{array}$ & AKI & Arrhythmias & $\begin{array}{l}\text { ICU stay, } \\
\text { vent. time }\end{array}$ & Mortality \\
\hline \multicolumn{10}{|c|}{ Meta-analyses comparing MiECC vs. cCPB } \\
\hline Biancari et al., 2009 (44) & 1,161 & & + & + & & & & & \pm \\
\hline Anastasiadis et al., 2014 (39) & 2,770 & + & + & & + & + & + & + & + \\
\hline Kowalewski et al., 2016 (41) & 12,929 & & & + & \pm & + & + & & + \\
\hline \multicolumn{10}{|c|}{ Studies comparing MiECC vs. OPCAB } \\
\hline van Bover et al., 2013 (50) & 60 & \pm & & & + & & & + & \\
\hline Wittwer et al., 2013 (51) & 120 & \pm & \pm & \pm & \pm & \pm & \pm & \pm & \\
\hline Formica et al., 2013 (52) & 61 & \pm & \pm & & \pm & & \pm & \pm & \\
\hline $\begin{array}{l}\text { Kowalewski et al., } 2016 \\
\text { (network meta-analysis) (41) }\end{array}$ & 11,676 & & & $+^{*}$ & $+^{*}$ & $+^{*}$ & $+^{*}$ & & $+^{*}$ \\
\hline
\end{tabular}

As indicated, clinical benefit becomes more evident as the number of included patients is increasing; mortality is the ultimate endpoint that is becoming evident in large-scale analyses. + , denotes benefit for MiECC; $+^{\star}$, denotes benefit after probability analysis for the hierarchy of treatments; \pm , denotes benefit for MiECC not reaching statistical significance. AKI, acute kidney injury; ICU, intensive care unit; MiECC, minimal invasive extracorporeal circulation; CCPB, conventional cardiopulmonary bypass; vent., ventilation.

lower cost and higher effectiveness) in coronary surgery (53). Moreover, MiECC was associated with improved quality of life postoperatively (54). Considering valve surgery, the largest meta-analysis published by Wang et al. in 2016 including 1,011 patients evidenced that MiECC was associated with a significant reduction in ICU and total hospital stay (55). Expected results of the ongoing largescale COMICS trial (ISRCTN92590475), which is an international, multicentre, randomized, controlled parallel group study, will further clarify the clinical effects of using MiECC in coronary and aortic valve surgery.

Regarding clinical results of MICS on MiECC, the largest prospective randomized study was published by Baumbach et al. in 2016 and randomized 200 patients undergoing isolated MICS aortic or mitral procedures on MiECC or cCPB (56). MiECC was associated with reduced hemodilution and inflammatory response as well as improved clinical outcome as evidenced by shorter duration of ventilatory support $(7.7 \pm 8.4 v s$. $9.3 \pm 12.9$ hours;
$\mathrm{P}=0.01)$ and ICU stay $(1.2 \pm 1.2$ vs. $2.2 \pm 3.8$ days; $\mathrm{P}=0.05)$. Berretta et al. have recently reported results from 288 consecutive patients undergoing MICS AVR on MiECC $(\mathrm{n}=102) v s$. $\mathrm{cCPB}(\mathrm{n}=186)(57)$. MiECC promoted ultrafast-track recovery $(60.8 \%$ vs. $26.9 \% ; \mathrm{P}<0.001)$ and it was associated with improved clinical outcomes in terms of postoperative rate of bleeding requiring revision $(0 \%$ vs. $5.3 \% ; \mathrm{P}=0.03)$, need for blood transfusions $(32.7 \%$ vs. $44 \% ; \mathrm{P}=0.04)$ and incidence of postoperative atrial fibrillation $(30.1 \%$ vs. $44.1 \% ; \mathrm{P}=0.034)$. In a smallerscale retrospective study including 40 patients, Starinieri et al. reported reduced intraoperative blood loss and need for blood transfusion in patients undergoing MICS AVR on MiECC compared to cCPB (58). The same group recently published excellent results from a large series of 342 patients undergoing TECAB on MiECC, of whom 289 had multiple grafts CABG (20). They reported no conversion to sternotomy, while incidence of surgical revision, graft failure, and 30-day mortality was $7.3 \%$, 
$1.5 \%$, and $1.8 \%$, respectively. Considering up-to-date clinical evidence, there is clear preliminary data indicating that MICS when combined with MiECC represents a safe and effective strategy that exhibit a synergistic effect towards further improving clinical outcome. This combination is considered a strategy towards a "more physiologic" cardiac surgery.

\section{Evidenced-based clinical advantages of MiECC}

Use of MiECC over cCPB has been already incorporated in clinical practice guidelines. According to the recent joint guidelines by the European Societies of all three stakeholders of the cardiac OR, that is EACTS, EACTA and EBCP (which is a rather unique achievement that gives extra credibility to the recommendations) (59): MiECC should be considered over standard cCPB systems to increase the biocompatibility of ECC (Class of recommendation: IIA, Level of evidence: B); MiECC should be considered over cCPB systems to reduce blood loss and the need for transfusion (Class of recommendation: IIA, Level of evidence: B); a combination of MiECC features-such as coating, the centrifugal pump, the separation of cardiotomy suction blood and use of closed systems-should be considered to improve cCPB (Class of recommendation: IIA, Level of evidence: C). The hematologic effects of MiECC in limiting hemodilution and maintaining hematocrit, thus significantly reducing perioperative transfusion rate, have also been integrated by EACTS/EACTA Task Force (28). In the same context, the Society of Cardiovascular Anesthesiologists in their recently published summary statement highly recommends MiECC as an effective blood conservation strategy in cardiac surgery (60). In general, it seems that when referring to optimal perfusion and to the future of $\mathrm{CPB}$, we are actually referring to the era of MiECC. Thus, MiECC has to be implemented as evidence-based strategy in cardiac surgery in overall as well as in MICS.

\section{Conclusions}

Clearly, MICS and MiECC are inter-related with a fraternal bond: "you can't have one without the other". They both target to minimize cardiac surgical trauma through a holistic (by preserving body's physiology) and not a single-dimensional approach (by avoiding full sternotomy or utilizing small incisions). Perceived clinical advantages of both strategies have been well-established in large clinical trials.
This combined strategy is portrayed in the common place that the major societies promoting "physiologic" cardiac surgery (ISMICS and MiECTiS) have reached during the last years. In his landmark speech at the $1^{\text {st }}$ MiECT Update Meeting in 2017, the President-Elect of ISMICS Dr Bob Kiaii pointed out that “...technology has made the heart team understand what can and must be done by coapting innovative devices and new methods; that is MICS, MiECC and change in conduct of surgery...".

Undoubtedly, "it takes two to tango" (15). Integration of MiECC can advance MICS from non-full sternotomy surgery offered to selected patients, to a "more physiologic" surgery, which represents the real face of modern cardiac surgery in the transcatheter era.

\section{Acknowledgments}

Funding: None.

\section{Footnote}

Provenance and Peer Review: This article was commissioned by the Guest Editors (Jason Ali and Yasir Abu-Omar) for the series "Minimally Invasive Cardiac Surgery" published in Fournal of Thoracic Disease. The article was sent for external peer review organized by the Guest Editors and the editorial office.

Conflicts of Interest: All authors have completed the ICMJE uniform disclosure form (available at http://dx.doi. org/10.21037/jtd-20-1830). The series "Minimally Invasive Cardiac Surgery" was commissioned by the editorial office without any funding or sponsorship. The authors have no other conflicts of interest to declare.

Ethical Statement: The authors are accountable for all aspects of the work in ensuring that questions related to the accuracy or integrity of any part of the work are appropriately investigated and resolved.

Open Access Statement: This is an Open Access article distributed in accordance with the Creative Commons Attribution-NonCommercial-NoDerivs 4.0 International License (CC BY-NC-ND 4.0), which permits the noncommercial replication and distribution of the article with the strict proviso that no changes or edits are made and the original work is properly cited (including links to both the formal publication through the relevant DOI and the license). 
See: https://creativecommons.org/licenses/by-nc-nd/4.0/.

\section{References}

1. Rosengart TK, Feldman T, Borger MA, et al. Percutaneous and minimally invasive valve procedure: a scientific statement from the American Heart Association council on cardiovascular surgery and anaesthesia, council on clinical cardiology, functional genomics and translational biology interdisciplinary working group, and quality of care and outcomes research interdisciplinary working group. Circulation 2008;117:1750-67.

2. D'Agostino RS, Jacobs JP, Badhwar V, et al. The Society of Thoracic Surgeons adult cardiac surgery database: 2019 update on outcomes and quality. Ann Thorac Surg 2019;107:24-32.

3. Brian BF. The engineering of cardiopulmonary bypass. In: Mongero LB, Beck JR. editors. On bypass: Advanced perfusion techniques. New Jersey: Humana Press Inc., 2008:1-28.

4. Smart NA, Dieberg G, King N. Long-term outcomes of on- versus off-pump coronary artery bypass grafting. J Am Coll Cardiol 2018;71:983-91.

5. Benedetto U, Puskas J, Kappetein AP, et al. Off-Pump versus on-pump bypass surgery for left main coronary artery disease. J Am Coll Cardiol 2019;74:729-40.

6. Taggart DP, Gaudino MF, Gerry S, et al. Ten-year outcomes after off-pump versus on-pump coronary artery bypass grafting: Insights from the Arterial Revascularization Trial. J Thorac Cardiovasc Surg 2020. [Epub ahead of print].

7. Shann K, Melnitchouk S. Advances in perfusion techniques: Minimally invasive procedures. Semin Cardiothorac Vasc Anesth 2014;18:146-52.

8. Sabik JF, Nemeh H, Lytle BW, et al. Cannulation of the axillary artery with a side graft reduces morbidity. Ann Thorac Surg 2004;77:1315-20.

9. De Somer F. Venous drainage-gravity or assisted? Perfusion 2011;26 Suppl 1:15-9.

10. Ganushchak YM, Körver EP, Yamamoto Y, et al. Versatile minimized system - a step towards safe perfusion. Perfusion 2016;31:295-9.

11. Vernick W, Atluri P. Robotic and minimally invasive cardiac surgery. Anesthesiol Clin 2013;31:299-320.

12. Misfeld M, Davierwala P. Crystalloid-based cardioplegia for minimally invasive cardiac surgery. Semin Thorac Cardiovasc Surg 2012;24:305-7.

13. Anastasiadis K, Argiriadou H, Deliopoulos A, et al.
Minimal invasive extracorporeal circulation (MiECC): the state-of-the-art in perfusion. J Thorac Dis 2019;11:S1507-14.

14. Grossi EA, Loulmet DF, Schwartz CF, et al. Evolution of operative techniques and perfusion strategies for minimally invasive mitral valve repair. J Thorac Cardiovasc Surg 2012;143:S68-70.

15. Anastasiadis K, Antonitsis P. MICS - MiECC: Can't have one without the other. Perfusion 2016;31:438-9.

16. Anastasiadis K, Antonitsis P, Deliopoulos A, et al. A multidisciplinary perioperative strategy for attaining "more physiologic" cardiac surgery. Perfusion 2017;32:446-53.

17. Phan K, Xie A, Tsai YC, et al. Ministernotomy or minithoracotomy for minimally invasive aortic valve replacement: a Bayesian network meta-analysis. Ann Cardiothorac Surg 2015;4:3-14.

18. Moscarelli M, Fattouch K, Gaudino M, et al. Minimal access versus sternotomy for complex mitral valve repair: a meta-analysis. Ann Thorac Surg 2020;109:737-44.

19. Argenziano M, Katz M, Bonatti J, et al. Results of the prospective multicenter trial of robotically assisted totally endoscopic coronary artery bypass grafting. Ann Thorac Surg 2006;81:1666-74.

20. Yilmaz A, Robic B, Starinieri P, et al. A new viewpoint on endoscopic CABG: technique description and clinical experience. J Cardiol 2020;75:614-20.

21. Anastasiadis K, Murkin J, Antonitsis P, et al. Use of minimal invasive extracorporeal circulation in cardiac surgery: principles, definitions and potential benefits. A position paper from the Minimal invasive Extra-Corporeal Technologies international Society (MiECTiS). Interact Cardiovasc Thorac Surg 2016;22:647-62.

22. Anastasiadis K, Antonitsis P, Argiriadou H, et al. Modular minimally invasive extracorporeal circulation systems; can they become the standard practice for performing cardiac surgery? Perfusion 2015;30:195-200.

23. Anastasiadis K, Antonitsis P, Argiriadou H. Surgical considerations. In: Anastasiadis K, Antonitsis P, Argiriadou H. editors. Principles of miniaturized extracorporeal circulation. Berlin: Springer, 2013:51-62.

24. Anastasiadis K, Antonitsis P, Argiriadou H. Anaesthetic management. In: Anastasiadis K, Antonitsis P, Argiriadou H. editors. Principles of miniaturized extracorporeal circulation. Berlin: Springer, 2013:63-71.

25. Anastasiadis K, Asteriou C, Antonitsis P, et al. Enhanced recovery after elective coronary revascularization surgery with minimal versus conventional extracorporeal circulation: a prospective randomized study. J Cardiothorac 
Vasc Anesth 2013;27:859-64.

26. Di Eusanio M, Vessella W, Carozza R, et al. Ultra fasttrack minimally invasive aortic valve replacement: going beyond reduced incisions. Eur J Cardiothorac Surg 2018;53:ii14-8.

27. Carozza R, Fazzi D, Pietrini A, et al. Minimally invasive aortic valve replacement: extracorporeal circulation optimization and minimally invasive extracorporeal circulation system evolution. Perfusion 2020;35:865-9.

28. Bauer A, Hausmann H, Schaarschmidt J, et al. Is 300 seconds ACT safe and efficient during MiECC procedures? Thorac Cardiovasc Surg 2019;67:191-202.

29. Argiriadou H, Antonitsis P, Deliopoulos A, et al. Pointof-care coagulation management during surgery with minimal invasive extracorporeal circulation. J Thorac Dis 2019;11:S1519-24.

30. Pagano D, Milojevic M, Meesters MI, et al. 2017 EACTS/ EACTA guidelines on patient blood management for adult cardiac surgery. Eur J Cardiothorac Surg 2018;53:79-111.

31. Anastasiadis K, Antonitsis P, Asteriou C, et al. Quantification of operational learning in minimal invasive extracorporeal circulation. Artif Organs 2017;41:628-36.

32. Anastasiadis K, Antonitsis P, Ranucci M, et al. Minimally invasive extracorporeal circulation (MiECC): towards a more physiologic perfusion. J Cardiothorac Vasc Anesth 2016;30:280-1.

33. Wiesenack C, Liebold A, Philipp A, et al. Four years' experience with a miniaturized extracorporeal circulation system and its influence on clinical outcome. Artif Organs 2004;28:1082-8.

34. Bauer A, Diez C, Schubel J, et al. Evaluation of hemodynamic and regional tissue perfusion effects of minimized extracorporeal circulation (MECC). J Extra Corpor Technol 2010;42:30-9.

35. Kara A, Akin S, Ince C. The response of the microcirculation to cardiac surgery. Curr Opin Anaesthesiol 2016;29:85-93.

36. De Backer D, Dubois MJ, Schmartz D, et al. Microcirculatory alterations in cardiac surgery: effects of cardiopulmonary bypass and anesthesia. Ann Thorac Surg 2009;88:1396-403.

37. Yuruk K, Bezemer R, Euser M, et al. The effects of conventional extracorporeal circulation versus miniaturized extracorporeal circulation on microcirculation during cardiopulmonary bypass-assisted coronary artery bypass graft surgery. Interact Cardiovasc Thorac Surg 2012;15:364-70.

38. Donndorf P, Kuhn F, Vollmar B, et al. Comparing microvascular alterations during minimal extracorporeal circulation and conventional cardiopulmonary bypass in coronary artery bypass graft surgery: a prospective, randomized study. J Thorac Cardiovasc Surg 2012;144:677-83.

39. Anastasiadis K, Antonitsis P, Haidich AB, et al. Use of minimal extracorporeal circulation improves outcome after heart surgery; a systematic review and meta-analysis of randomized controlled trials. Int J Cardiol 2013;164:158-69.

40. Ried M, Kobuch R, Rupprecht L, et al. Reduced 30-day mortality in men after elective coronary artery bypass surgery with minimized extracorporeal circulation - a propensity score analysis. BMC Cardiovascular Disorders 2012;12:17.

41. Kowalewski M, Pawliszak W, Raffa GM, et al. Safety and efficacy of miniaturized extracorporeal circulation when compared with off-pump and conventional coronary artery bypass grafting: evidence synthesis from a comprehensive Bayesian-framework network meta-analysis of 134 randomized controlled trials involving 22778 patients. Eur J Cardiothorac Surg 2016;49:1428-40.

42. Anastasiadis K, Antonitsis P, Bauer A, et al; Minimal invasive Extracorporeal Technologies international Society (MiECTiS). Minimal invasive extracorporeal circulation should become the standard practice in coronary revascularization surgery. Eur J Cardiothorac Surg 2016;50:189.

43. Benedetto U, Angeloni E, Refice S, et al. Is minimized extracorporeal circulation effective to reduce the need for red blood cell transfusion in coronary artery bypass grafting? Meta-analysis of randomized controlled trials. J Thorac Cardiovasc Surg 2009;138:1450-3.

44. Biancari F, Rimpilainen R. Meta-analysis of randomised trials comparing the effectiveness of miniaturised versus conventional cardiopulmonary bypass in adult cardiac surgery. Heart 2009;95:964-9.

45. Zangrillo A, Garozzo FA, Biondi-Zoccai G, et al. Miniaturized cardiopulmonary bypass improves shortterm outcome in cardiac surgery: a meta-analysis of randomized controlled studies. J Thorac Cardiovasc Surg 2010;139:1162-9.

46. Harling L, Warren OJ, Martin A, et al. Do miniaturized extracorporeal circuits confer significant clinical benefit without compromising safety? A meta-analysis of randomized controlled trials. ASAIO J 2011;57:141-51.

47. Mazzei V, Nasso G, Salamone G, et al. Prospective randomized comparison of coronary bypass grafting with minimal extracorporeal circulation system (MECC) versus 
off-pump coronary surgery. Circulation 2007;116:1761-7.

48. Formica F, Broccolo F, Martino A, et al. Myocardial revascularization with miniaturized extracorporeal circulation versus off pump: evaluation of systemic and myocardial inflammatory response in a prospective randomized study. J Thorac Cardiovasc Surg 2009;137:1206-12.

49. Wittwer T, Choi YH, Neef K, et al. Off-pump or minimized on-pump coronary surgeryeinitial experience with Circulating Endothelial Cells (CEC) as a supersensitive marker of tissue damage. J Cardiothorac Surg 2011;6:142.

50. van Boven WJ, Gerritsen WB, Driessen AH, et al. Minimised closed circuit coronary artery bypass grafting in the elderly is associated with lower levels of organspecific biomarkers: a prospective randomised study. Eur J Anaesthesiol 2013;30:685-94.

51. Wittwer T, Sabashnikov A, Rahmanian PB, et al.

Less invasive coronary artery revascularization with a minimized extracorporeal circulation system: preliminary results of a comparative study with off-pump-procedures. J Cardiothorac Surg 2013;8:75.

52. Formica F, Mariani S, Broccolo F, et al. Systemic and myocardial inflammatory response in coronary artery bypass graft surgery with miniaturized extracorporeal circulation: differences with a standard circuit and offpump technique in a randomized clinical trial. ASAIO J 2013;59:600-606.

53. Anastasiadis K, Fragoulakis V, Antonitsis P, et al. Coronary artery bypass grafting with minimal versus conventional extracorporeal circulation; an economic analysis. Int J Cardiol 2013;168:5336-43.

Cite this article as: Anastasiadis K, Antonitsis P, Deliopoulos A, Argiriadou H. From less invasive to minimal invasive extracorporeal circulation. J Thorac Dis 2021;13(3):19091921. doi: 10.21037/jtd-20-1830
54. Anastasiadis K, Antonitsis P, Kostarellou G, et al. Minimally invasive extracorporeal circulation improves quality of life after coronary artery bypass grafting. Eur J Cardiothorac Surg 2016;50:1196-203.

55. Wang C, Hua K, Yin L, et al. A meta-analysis of miniaturized versus conventional extracorporeal circulation in valve surgery. Ann Thorac Surg 2016;102:2099-108.

56. Baumbach H, Rustenbach CJ, Ahad S, et al. Minimally invasive extracorporeal bypass in minimally invasive heart valve operations: a prospective randomized trial. Ann Thorac Surg 2016;102:93-100.

57. Berretta P, Cefarelli M, Montecchiani L, et al. Minimally invasive versus standard extracorporeal circulation system in minimally invasive aortic valve surgery: a propensity score-matched study. Eur J Cardiothorac Surg 2020;57:717-23.

58. Starinieri P, Declercq PE, Robic B, et al. A comparison between minimized extracorporeal circuits and conventional extracorporeal circuits in patients undergoing aortic valve surgery: is 'minimally invasive extracorporeal circulation' just low prime or closed loop perfusion? Perfusion 2017;32:403-8.

59. Wahba A, Milojevic M, Boer C, et al; EACTS/EACTA/ EBCP Committee Reviewers. 2019 EACTS/EACTA/ EBCP guidelines on cardiopulmonary bypass in adult cardiac surgery. Eur J Cardiothorac Surg 2020;57:210-51.

60. Raphael J, Mazer CD, Subramani S, et al. Society of Cardiovascular Anesthesiologists Clinical Practice Improvement Advisory for Management of Perioperative Bleeding and Hemostasis in Cardiac Surgery Patients. Anesth Analg 2019;129:1209-21. 